Shyam Lal*, Sudhir Kumar and Zahid A. Khan

\title{
Microstructure evaluation, thermal and mechanical characterization of hybrid metal matrix composite
}

https://doi.org/10.1515/secm-2017-0210

Received June 21, 2017; accepted January 2, 2018; previously published online August 8, 2018

\begin{abstract}
In this paper, an inert gas assisted electromagnetic stir casting process is adapted for manufacturing a cast hybrid metal matrix composite (MMC) using $\mathrm{Al}_{2} \mathrm{O}_{3}$ and $\mathrm{SiC}$ particulates as a hard phase reinforcement in $\mathrm{Al} 7075$ alloy metal matrix. Four different samples containing 5, 10, 15 and $20 \mathrm{wt} \%$ of $\mathrm{Al}_{2} \mathrm{O}_{3}$ and $\mathrm{SiC}$ with $\mathrm{Al} 7075$ alloy composites were fabricated. The characterizations for all the samples were carried out through optical microstructure, scanning electron microscopy (SEM) fractograph, X-ray diffraction (XRD) analysis, differential thermal analysis (DTA) analysis and mechanical properties. The results revealed that the particles are uniformly distributed in the matrix. No peaks of $\mathrm{Al}_{4} \mathrm{C}_{3}$ were found. There is negligible loss of material in the composite. The tensile strength and microhardness of the hybrid composite are higher by $65.7 \%$ and $13.5 \%$, respectively, when compared to its cast metal matrix $\mathrm{Al} 7075$ alloy.
\end{abstract}

Keywords: Al7075; DTA; electromagnetic stir casting; hybrid composite; XRD.

\section{Introduction}

Composite materials are engineered materials having a combination of two or more chemically distinct and insoluble phases. The ceramic reinforcement has high strength and high modulus whereas the metal matrix is ductile. The resulting composite material has mechanical properties intermediate to the matrix alloy and the ceramic reinforcement. In metal matrix composites (MMCs), the primary function of the reinforcement is to support most of the applied

*Corresponding author: Shyam Lal, Department of Mechanical Engineering, Noida Institute of Engineering and Technology, Greater Noida, India, e-mail: shyamlal561@gmail.com

Sudhir Kumar: Department of Mechanical Engineering, Greater Noida Institute of Technology, Greater Noida, India

Zahid A. Khan: Department of Mechanical Engineering, Faculty of Engineering and Technology, Jamia Millia Islamia, New Delhi, India load, while that of the matrix is to bind the reinforcement together [1]. Aluminum is widely used as a metal matrix because of its light weight, good mechanical properties and formability, economy and high resistance to environmental degradation. Also aluminum has the capability to incorporate a wide variety of reinforcing agents such as $\mathrm{Al}_{2} \mathrm{O}_{3}, \mathrm{SiC}$, graphite fibers, whiskers and other particles. Hybrid MMC is obtained by incorporating two or more different kinds of reinforcements in a single matrix. Hybrids have a better all-round combination of mechanical properties than composites containing only a single reinforcement. Composite materials find wide applications in aircraft, space vehicles, offshore structures, piping, electronics, automobiles, boats and sporting goods [2, 3]. Cambronero et al. [4] produced MMC through the powder metallurgy route using $7015 \mathrm{Al}-$ alloy powder with $5 \mathrm{wt} \% \mathrm{Si}_{3} \mathrm{~N}_{4}, \mathrm{TiB}_{2}$ and $\mathrm{B}_{4} \mathrm{C}$ ceramic powder (8-10 $\mu \mathrm{m}$ size). Ceramic powders are uniformly distributed in AA7015 matrix and no porosity was found. The authors further observed that ceramic addition decreases electrical conductivity, lowers tensile strength, decreases plastic deformation, but has a better wear behavior when compared with heat treated $\mathrm{T}_{6}$ AA7015 Al-alloy [4]. Kumar and Balasubramanian [5] fabricated AA7075/ $\mathrm{SiC}_{\mathrm{p}}$ composite by the powder metallurgy route and developed a mathematical model to evaluate the wear rate. The authors concluded that particle size has an inversely proportional relationship with wear rate, while the volume fraction of reinforcement and sliding speed are directly proportional with the wear rate. Kalkanli and Yllmaz [6] prepared Al7075 composite with $10 \mathrm{wt} \%, 15 \mathrm{wt} \%, 20 \mathrm{wt} \%$ and $30 \mathrm{wt} \% \mathrm{SiC}$ through vertical pressure die/squeeze casting.

Characterizations of samples were carried out through scanning electron microscopy (SEM) analysis, X-ray diffraction (XRD) analysis and mechanical properties. The results revealed that no $\mathrm{Al}_{4} \mathrm{C}_{3}$ was present in the sample and hardness increased with an increased in $\mathrm{SiC}$ content [6]. Karthikeyan et al. [7] made a calorimetric study of 7075 $\mathrm{Al} / \mathrm{SiC}_{\mathrm{p}}$ composite fabricated by the stir casting technique having $10 \%, 15 \%$ and $20 \%$ volume fractions of $\mathrm{SiC}_{\mathrm{p}}$ of $20 \mu \mathrm{m}$ average size. The cast billets were hot extruded in a ratio of 20:1. After keeping the cast billets in a soaking temperature of $420^{\circ} \mathrm{C}$ for 30 min duration, the authors observed that heat capacity of all the composites is less than the 
alloy. The presence of $\mathrm{SiC}_{\mathrm{p}}$ reduces the heat capacity with an increase in its volume percentages [7]. Dasgupta [8] made an attempt to establish the stretch, limit and path forward for 7075 Al-alloy with $10 \%$ volume $\mathrm{SiC}(20-40 \mu \mathrm{m}$ size) fabricated through the liquid metallurgy technique. The alloy and composite were subjected to heat treatment (aging and tempering) and extrusion. The cast composite exhibited near uniform distribution of the particulates within the matrix. On aging the 7075 composite, dissolution of grain boundaries was observed together with coagulation of precipitates around the $\mathrm{SiC}$ dispersoids. The bulk hardness of the composite increased by $40 \%$ and extruding them further increased the value by some $25 \%$ when compared with the matrix alloy. Ultimate tensile strength (UTS) testing revealed that homogenization increased the UTS, but the extrusion process resulted in a slight decrease [8]. Hossein and Asghar [9] fabricated $\mathrm{Al} 7075 / \mathrm{TiB}_{2}$ composite via friction stir processing. Ceramic material $\mathrm{TiB}_{2}$ powder with an average particle size of $2.62 \mu \mathrm{m}$ was used. The authors observed that distribution of particles improved with increasing the rotational speed, with no obvious microporosity defect. Microhardness was $179 \mathrm{HV}$ in the nugget zone, while it was $64 \mathrm{HV}$ average of as received $\mathrm{Al} 7075$ alloy. Results of the tensile test revealed that the addition of reinforcement significantly increased the yield strength of the composite from $91 \mathrm{MPa}$ to $184 \mathrm{MPa}$ [9]. Karthigeyan et al. [10] studied the mechanical properties and microstructure of the Al-7075 alloy matrix composite reinforced with short basalt fiber (SBF). The authors used the liquid metallurgy route to fabricate the composite using SBF of $1.5-2 \mathrm{~mm}$ length and $2 \%, 4 \%$ and $6 \%$ volume fraction. The authors observed the composite to be near dense having relatively low volumetric porosity. The UTS of the composite was improved by $65.51 \%$ with the addition of $6 \%$ volume fraction SBF over the un-reinforced matrix. The fractured surface under tensile loading of the cast $\mathrm{Al} 7075$ alloy and composite showed the presence of equiaxed and shallow dimples [10]. Deshmanya and Purohit [11] studied the effect of forging on microhardness of $\mathrm{Al} 7075$ based $\mathrm{Al}_{2} \mathrm{O}_{3}$ reinforced composite produced by stir casting. The particulates used were in the range of $36 \mu \mathrm{m}-72 \mu \mathrm{m}$ size, weight percentage ranging from $5 \%$ to $15 \%$, forging temperatures in the range of $385^{\circ} \mathrm{C}-425^{\circ} \mathrm{C}$ and reduction in area ranging from $10 \%$ to $50 \%$. The authors developed a hardness model and concluded that the effect of reinforcement size is more pronounced up to $60 \mu \mathrm{m}$ and after that it has a tendency to reduce the hardness, achieving maximum hardness value with a $50 \mu \mathrm{m}$ particle size. The maximum hardness is 140 VHN at $15 \%$ weight proportion. Also the microhardness value is around $135-140 \mathrm{VHN}$ corresponding to $425^{\circ} \mathrm{C}$ forging temperature and $15 \%$ reduction in the area due to forging [11]. Kumar et al. [12] fabricated a $7075 \mathrm{Al}$ alloy composite with $10 \mathrm{wt} \%$ and $15 \mathrm{wt} \% \mathrm{SiC}$ by the stir casting process. The resulting as cast composite structures are analyzed using SEM, XRD, differential thermal analysis (DTA) and electron probe microscopic analysis. The SEM image of the as cast 7075 Al-alloy $\mathrm{SiC}_{\mathrm{p}}$ composite microstructure showed excellent $\mathrm{SiC}_{\mathrm{p}}$ distribution in $7075 \mathrm{Al}$ alloy matrix. Energy dispersive X-ray (EDX) spot analysis suggested the absence of $\mathrm{Al}_{4} \mathrm{C}_{3}$ phases [12].

Based on the literature review, no researcher has fabricated $7075 / \mathrm{SiC} / \mathrm{Al}_{2} \mathrm{O}_{3}$ hybrid composite using the inert gas assisted electromagnetic stir casting process. Electromagnetic stirring has dominant industrial application because of its high efficiency, non-contact stirring, easy operation and parametric stability. Structures produced by electromagnetic stirring are non-dendritic. In this study, with the help of the inert gas assisted electromagnetic stir casting process, the rotational electromagnetic field was used to create a strong vortex in to the $7075 \mathrm{Al}$ alloy matrix melt for incorporating the reinforcing particles ( $\mathrm{SiC}$ and $\mathrm{Al}_{2} \mathrm{O}_{3}$ ) of various wt $\%$ to produce the hybrid composite. The composites were characterized through microstructure, DTA, XRD, SEM analysis and mechanical properties.

\section{Materials and methods}

\subsection{Materials}

Commercially available wrought aluminum alloy 7075 was used as the matrix alloy for the fabrication of hybrid MMC. This is the most common Al-alloy of the 7XXX series having great potential to be utilized in the aerospace and the automotive industries because of its high strength to weight ratio and good resistance to corrosion. Stronger matrix alloys tend to produce stronger composites. The wt $\%$ composition of $7075 \mathrm{Al}$ alloy is shown in Table 1.

Silicon carbide and aluminum oxide in particulate form are used as reinforcements to produce hybrid MMC. These

Table 1: Composition of aluminum alloy Al7075.

\begin{tabular}{lrrrrrrr}
\hline Zn (wt\%) & Cu (wt\%) & Mg (wt\%) & Cr (wt\%) & Si (wt\%) & Ti (wt\%) & Fe (wt\%) & Al \\
\hline 5.65 & 1.78 & 2.51 & 0.27 & 0.36 & 0.19 & 0.48 & Balance \\
\hline
\end{tabular}


Table 2: Various physical properties of $\mathrm{SiC}$ and $\mathrm{Al}_{2} \mathrm{O}_{3}$.

\begin{tabular}{lrrrrrrr}
\hline Reinforcement & $\begin{array}{r}\text { Density } \\
\left(\mathbf{k g} / \mathbf{m}^{3}\right)\end{array}$ & $\begin{array}{r}\text { Elastic modulus } \\
(\mathrm{GPa})\end{array}$ & $\begin{array}{r}\text { Compressive } \\
\text { strength }(\mathrm{GPa})\end{array}$ & $\begin{array}{r}\text { Hardness } \\
\left(\mathbf{k g} / \mathbf{m m}^{2}\right)\end{array}$ & $\begin{array}{r}\text { Melting point } \\
\left({ }^{\circ} \mathrm{C}\right)\end{array}$ & $\begin{array}{r}\text { Specific heat } \\
(\mathbf{J} / \mathbf{k g ~ K})\end{array}$ & $\begin{array}{r}\text { Co-efficient of thermal } \\
\text { expansion }\left(\times 10^{-6} \mathrm{~K}^{-1}\right)\end{array}$ \\
\hline $\mathrm{SiC}$ & 3210 & 410 & 3900 & 2800 & 2730 & 750 & 4.0 \\
$\mathrm{Al}_{2} \mathrm{O}_{3}$ & 3890 & 375 & 2600 & 1440 & 2040 & 880 & 8.4 \\
\hline
\end{tabular}

reinforcements have $20-40 \mu \mathrm{m}$ size particles and are used in combination in the ratio of 1:1. Silicon carbide is cost effective when being used on a large scale, followed by aluminum oxide. These ceramic reinforcements have a high elastic modulus, high compressive strength and high hardness. The various physical properties are as shown in Table 2.

\subsection{Experimental set up of inert gas assisted electromagnetic stirring system}

The experimental set of the inert gas assisted electromagnetic stirring system (NIET Greater Noida, UP, India) is shown in Figure 1. The melting process was carried out in a graphite crucible using an electric resistance heating type muffle furnace. The muffle furnace was flushed with argon gas and also, the crucible was blown with inert gas argon. The de-gassing of melt was carried out by inert gas (argon) for $10 \mathrm{~min}$ before the introduction of reinforcement in to it. Also, the inert gas atmosphere was maintained above the melt surface during the synthesis of the hybrid composite to minimize oxidation of aluminum. When the melting was achieved at a temperature of $715^{\circ} \mathrm{C}$, the melt was quickly lifted from the furnace and placed inside the motor housing which was placed on a stand. The longitudinal axis of the motor housing was kept vertical as shown in Figure 1. The supply was switched on and the voltage on the regulator adjusted to $60 \mathrm{~V}$; molten metal starts rotating in the crucible when subjected to Lorentz forces. The three phase induction motor (15 kW rating) housing is a source of rotational electromagnetic field. A forced vortex

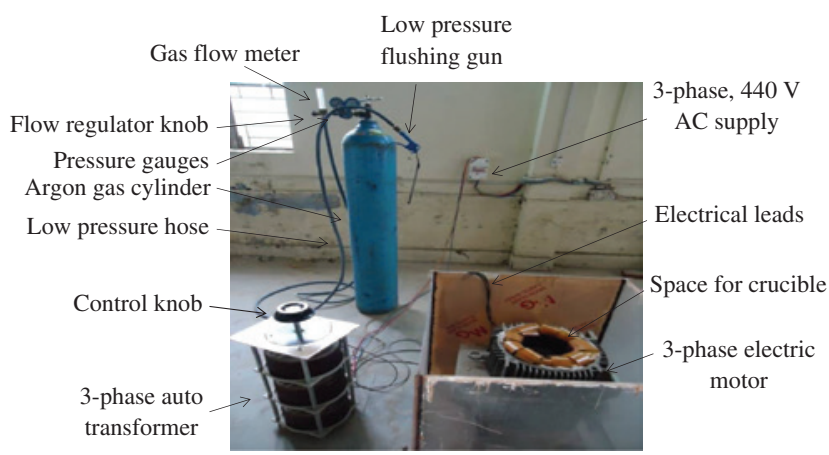

Figure 1: Experimental set up of inert gas assisted electromagnetic stir casting process. is generated in the melt. The reinforcement material particulates $\left(\mathrm{Al}_{2} \mathrm{O}_{3}\right.$ and $\left.\mathrm{SiC}\right)$ were mixed thoroughly and preheated to a temperature of $900^{\circ} \mathrm{C}$ before induction into the melt. Preheating the SiC particles assists in removing surface impurities, desorption of gases and alters the surface composition by formation of an oxide layer on the surface [13]. The formed oxide layer helps in improving the wettability of $\mathrm{SiC}$ by the melt [14-16]. The addition of preheated alumina particles in an Al-Mg melt has also been found to improve the wetting of alumina $[17,18]$.

The thoroughly mixed preheated reinforcement phase $\left(\mathrm{Al}_{2} \mathrm{O}_{3}+\mathrm{SiC}\right)$ particulate at a controlled rate is induced into the melt at the periphery of the vortex. The electromagnetic stirring is continued for around $6 \mathrm{~min}$ after the reinforcement induction phase is finished. The power to the stirring system is kept on till melt is reached to solidus state whereby the stirring effect is no longer achievable and practically diminishes. After achieving solidification, the crucible is lifted from the electromagnetic stirrer and allowed to cool in the air. Four different compositions namely $5 \mathrm{wt} \%, 10 \mathrm{wt} \%, 15 \mathrm{wt} \%$ and $20 \mathrm{wt} \%$ of hybrid MMC were successfully fabricated using equal wt $\%$ of $\mathrm{SiC}$ and $\mathrm{Al}_{2} \mathrm{O}_{3}$ particulates in $\mathrm{Al}-7075$ metal matrix. The four cast ingots of hybrid composites are as shown in Figure 2. After that, specimens are prepared for microstructural, XRD and DTA examination.

\section{Characterization of hybrid composites}

\subsection{Microstructure}

Metallographic samples were taken from each ingot. The specimens for microscopic examination were prepared

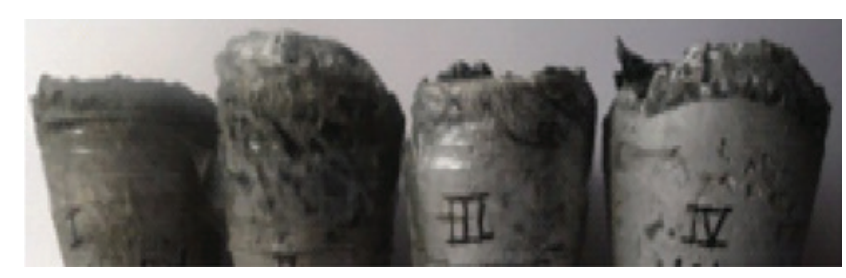

Figure 2: Cast ingots of $\mathrm{Al} 7075 / \mathrm{Al}_{2} \mathrm{O}_{3} / \mathrm{SiC}$ hybrid composite. 
by adopting a standard metallographic procedure. Wellcleaned samples were etched with Keller reagent (NIET Greater Noida, UP, India) to reveal the microstructure. Keller reagent was a solution mixture of $1 \%$ hydrofluoric acid, 1.5\% hydrochloric acid, 2.5\% nitric acid and a balance of distilled water. The specimens were observed for the microstructure using a radical metallurgical microscope fitted with an Inter video Win DVR CCD digital camera (NIET Greater Noida, UP, India) which is interfaced to a personal computer for image capture. Figure $3 \mathrm{~A}-\mathrm{D}$ shows the microstructures of hybrid MMC samples.

Because of the difference in density between the two reinforcements, the uniform distribution of reinforcements is the most important factor in the fabrication of hybrid composites.

Microstructure images show the distribution of reinforcements in the matrix. The $\mathrm{SiC}$ and $\mathrm{Al}_{2} \mathrm{O}_{3}$ particles are shown as black and ivory white, respectively. These are uniformly distributed in the matrix. Good bonding between the reinforcement particles and the matrix alloy is observed. No porosity or clustering of particles is observed in the optical examination at low wt $\%$ addition of reinforcement, however in some places, particle agglomeration is seen with voids at $20 \mathrm{wt} \%$ addition of reinforcement particulates.

\subsection{XRD analysis}

$\mathrm{XRD}$ is commonly used to identify phases in materials by comparing their diffraction patterns with those from known references. The intensity of the XRD peak obtained for a given phase depends on its proportion and size in the material. A Bruker AXS D-8 advance diffractometer with $\mathrm{CuK}_{\alpha}$ (Facility at Institute Instrumentation centre, IIT Roorkee, India) radiation and a nickel filter at $20 \mathrm{~mA}$ and $35 \mathrm{kV}$ at $25^{\circ} \mathrm{C}$ room temperature was used to obtain the diffraction patterns. The samples were scanned with a scanning speed of $1.5 \mathrm{kcps}$ in the $2 \theta$ range of $10-100^{\circ}$ at $2^{\circ} /$ min goniometer rotation and the intensities were recorded at a chart speed of $20 \mathrm{~mm} / \mathrm{min}$. The diffractometer being interfaced with Brucker Diffract plus $\mathrm{X}$-ray diffraction software provides " $\mathrm{d}$ " values directly on the diffraction pattern. X-ray diffractometry curves are shown in Figure 4A-D for the hybrid MMCs of $5 \mathrm{wt} \%, 10 \mathrm{wt} \%, 15 \mathrm{wt} \%$ and $20 \mathrm{wt} \%$ of $\mathrm{SiC}$ and $\mathrm{Al}_{2} \mathrm{O}_{3}$ particulates.

The highest peak confirms the presence of the base element aluminum of the matrix alloy Al7075. The other constituent elements $\mathrm{Fe}, \mathrm{Mg}, \mathrm{Si}, \mathrm{Cr}, \mathrm{Zn}, \mathrm{Cu}$ and Ti are confirmed by smaller peaks. The reinforcement $\mathrm{Al}_{2} \mathrm{O}_{3}$ and $\mathrm{SiC}$ are confirmed at their respective peaks. A direct reaction between aluminum and $\mathrm{SiC}$ can occur during the fabrication process producing a solid phase $\mathrm{Al}_{4} \mathrm{C}_{3}[19]$. This
A

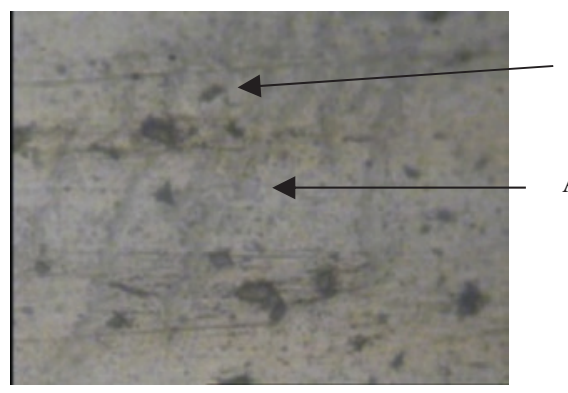

C

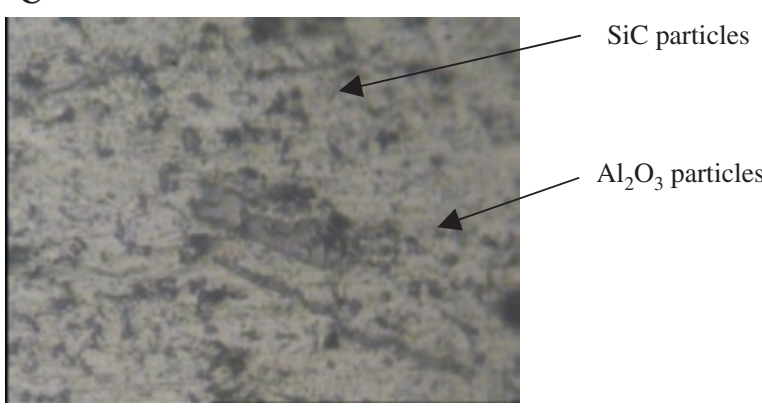

B
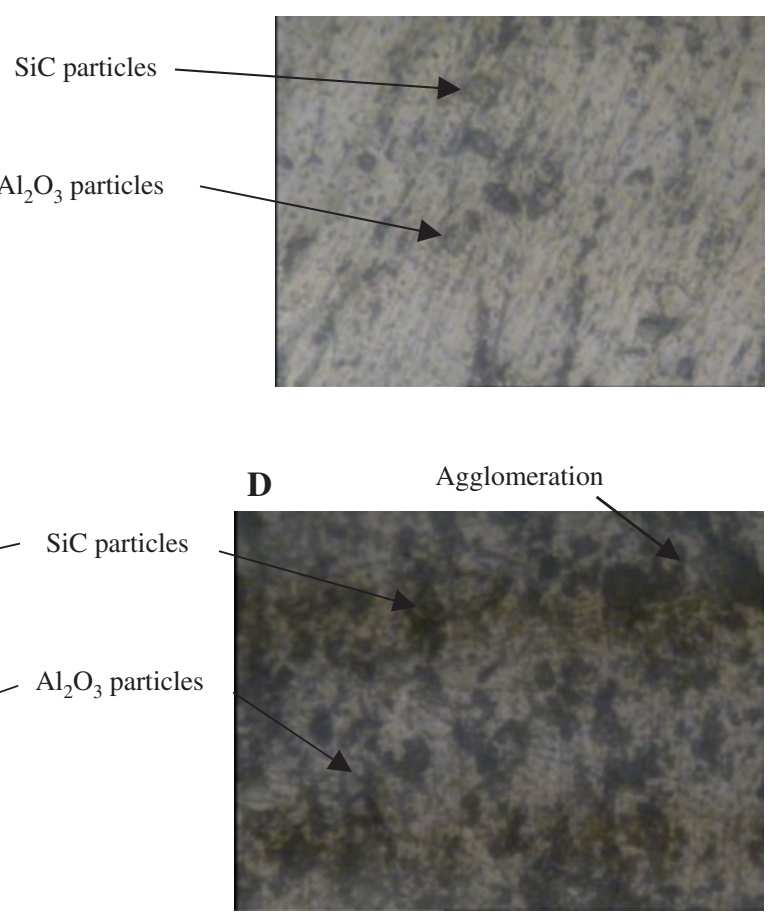

Figure 3: Microstructures of hybrid metal matrix composites (MMCs) of (A) $5 \mathrm{wt} \%$, (B) $10 \mathrm{wt} \%$, (C) $15 \mathrm{wt} \%$, and (D) $20 \mathrm{wt} \%$ of the $\mathrm{Al}_{2} \mathrm{O}_{3}+\mathrm{SiC}$ reinforcements in $7075 \mathrm{Al}$-alloy matrix. 

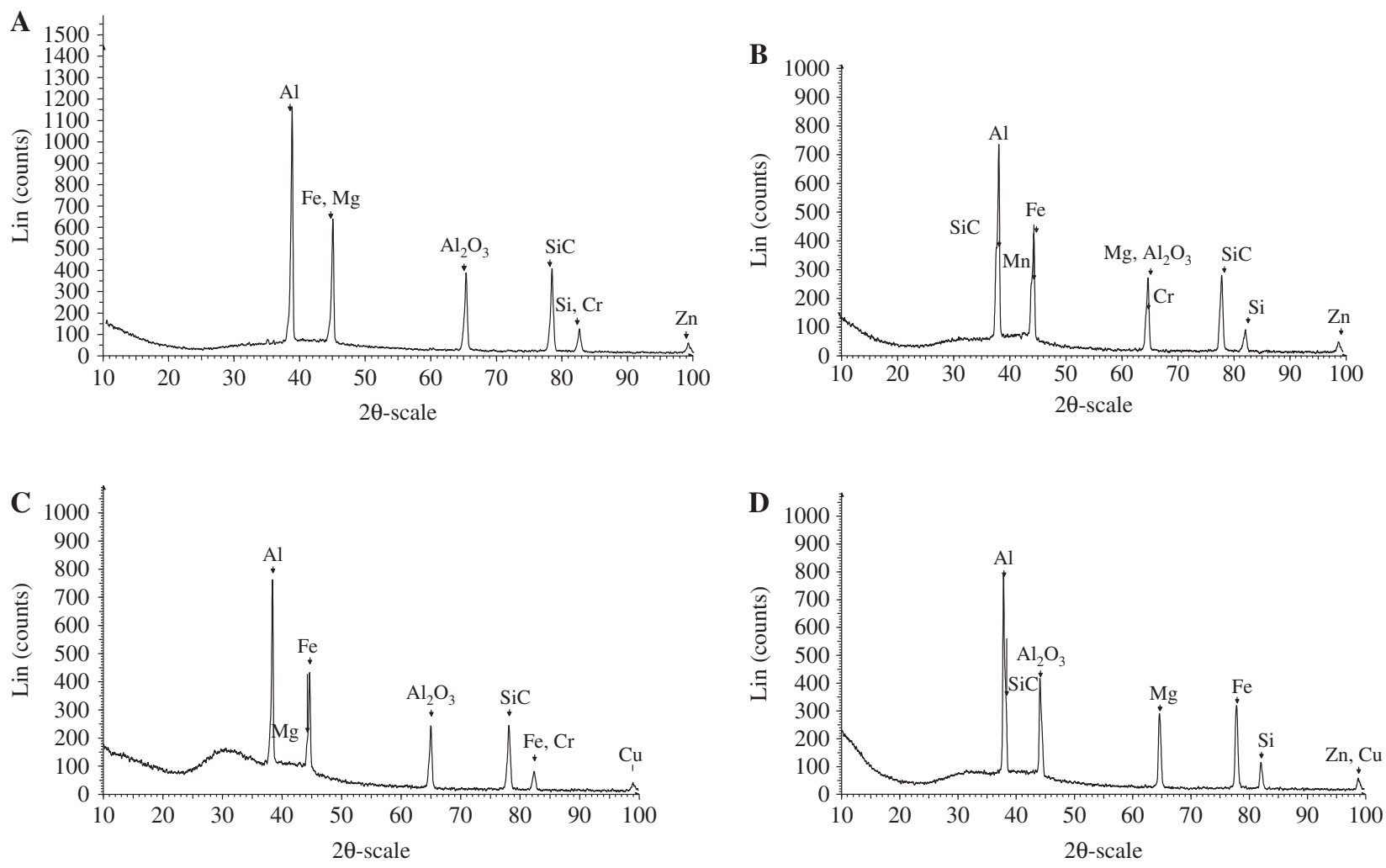

Figure 4: X-ray diffractometry curves of $\mathrm{Al} 7075 / \mathrm{SiC} / \mathrm{Al}_{2} \mathrm{O}_{3}$ hybrid composite: (A) $5 \mathrm{wt} \%$, (B) $10 \mathrm{wt} \%$, (C) $15 \mathrm{wt} \%$, (D) $20 \mathrm{wt} \%$.

interfacial reaction product reacts with water (even with moisture at room temperature) producing another solid phase $\mathrm{Al}(\mathrm{OH})_{3}$. This interfacial reaction product produces an adverse effect on the physical and mechanical properties of the composite leading to its degradation. Thus, formation of $\mathrm{Al}_{4} \mathrm{C}_{3}$ is to be contained. Preheating the $\mathrm{SiC}$ to $900^{\circ} \mathrm{C}$ before induction into the melt is one such technique. In this way, the interface of $\mathrm{SiC}$ is modified by preoxidation, forming a layer of $\mathrm{SiO}_{2}$ on it. This will protect the $\mathrm{SiC}$ particles from aluminum attack, thus arresting the formation of $\mathrm{Al}_{4} \mathrm{C}_{3}$ [20-23]. No peaks of brittle phase $\mathrm{Al}_{4} \mathrm{C}_{3}$ are seen in the X-ray diffraction pattern.

\subsection{Thermogravimetric analysis, derivative thermogravimetric analysis and DTA}

Thermal analysis was performed in the temperature range of $23-1000^{\circ} \mathrm{C}$ at a heating rate of $25^{\circ} \mathrm{C} / \mathrm{min}$ on a Perkin Elmer apparatus (Facility at Institute Instrumentation centre, IIT Roorkee, India). All hybrid MMC samples were subjected to thermogravimetric analysis (TG), derivative thermogravimetric analysis (DTG) and DTA to find information regarding their thermal degradation characteristics. A heating rate of $25^{\circ} \mathrm{C} / \mathrm{min}$ under air supply $200 \mathrm{ml} / \mathrm{min}$ was employed as the degradation rate and temperature difference. The temperature difference occurs due to endothermic and/or exothermic enthalpy transitions or reactions such as dehydration, dissociation or decomposition, oxidation or other chemical reactions. The reference material was alumina powder. TG, DTG and DTA curves for a sample $5 \mathrm{wt} \%$ hybrid MMC are shown in Figure 5A.

The figure shows the DTA curve has two exothermic peaks at $315^{\circ} \mathrm{C}$ and $903^{\circ} \mathrm{C}$, and one endothermic peak at $678^{\circ} \mathrm{C}$. The curve indicates that phase transformation takes place at $678^{\circ} \mathrm{C}$. The TG curve indicates $100 \%$ mass at $24^{\circ} \mathrm{C}$. Heating from $24^{\circ} \mathrm{C}$ to $100^{\circ} \mathrm{C}$ results in a minor increase in weight by $0.03 \%$ but from $100^{\circ} \mathrm{C}$ to $200^{\circ} \mathrm{C}$, loss of mass starts and the trend increases steeply from $200^{\circ} \mathrm{C}$ to $300^{\circ} \mathrm{C}$ whereby it has a loss of $1.48 \%$. This trend of loss of mass can be correlated to the exothermic peak of the DTA curve which occurs at $315^{\circ} \mathrm{C}$ and may be attributed to burning of some impurity. Between $300^{\circ} \mathrm{C}$ and $400^{\circ} \mathrm{C}$, the loss of mass trend tends to stabilize. Loss of mass is $0.12 \%$ between $400^{\circ} \mathrm{C}$ and $500^{\circ} \mathrm{C}$. From $500^{\circ} \mathrm{C}$ to $1005^{\circ} \mathrm{C}$ there is a gain in mass trend rising from $97.28 \%$ to $98.80 \%$, i.e. a total gain of $1.52 \%$. One composition step at $313^{\circ} \mathrm{C}$ and a decomposition step at $903^{\circ} \mathrm{C}$ are observed in the DTG curve.

Figure 5B shows TG, DTG and DTA curves for $10 \mathrm{wt} \%$ $\mathrm{SiC}$ and $\mathrm{Al}_{2} \mathrm{O}_{3}$ with $\mathrm{Al} 7075$ alloy. Here, the DTA curve has 
two broad exothermic peaks at $242^{\circ} \mathrm{C}$ and $314^{\circ} \mathrm{C}$ and one endothermic peak at $673^{\circ} \mathrm{C}$. The phase transformation takes place at $673^{\circ} \mathrm{C}$. The TG curve indicates that material is $100 \%$ at $23^{\circ} \mathrm{C}$ and remains so up to $100^{\circ} \mathrm{C}$ after that slight loss of mass trend occurs up to $200^{\circ} \mathrm{C}$ (loss of mass $=0.28 \%$ ). From $200^{\circ} \mathrm{C}$ to $400^{\circ} \mathrm{C}$ the loss of mass trend increased steeply, but after that, the trend somewhat flattened between $400^{\circ} \mathrm{C}$ and $600^{\circ} \mathrm{C}$. Beyond $600^{\circ} \mathrm{C}$, the gain of mass trend starts and continues up to $1000^{\circ} \mathrm{C}$ (total gain in mass $=0.81 \%$ ). Two broad composition peaks are observed on the DTG curve at $238^{\circ} \mathrm{C}$ and $308^{\circ} \mathrm{C}$.

Figure $5 \mathrm{C}$ shows TG, DTG and DTA curves for $15 \mathrm{wt} \%$ $\mathrm{SiC}$ and $\mathrm{Al}_{2} \mathrm{O}_{3}$ with $\mathrm{Al} 7075$ alloy.
The DTA curve has one exothermic peak at $326^{\circ} \mathrm{C}$ and an endothermic peak at $673^{\circ} \mathrm{C}$. The phase transformation occurs at $673^{\circ} \mathrm{C}$. The TG curve shows that material is $100 \%$ at $23^{\circ} \mathrm{C}$ and on heating from $23^{\circ} \mathrm{C}$ to $200^{\circ} \mathrm{C}$ results in a slight loss of mass trend (loss of mass $=0.35 \%$ ) which increases steeply between $200^{\circ} \mathrm{C}$ and $350^{\circ} \mathrm{C}$ approximately (loss of mass being around $2.46 \%$ ). Beyond $350^{\circ} \mathrm{C}$ and up to $500^{\circ} \mathrm{C}$, the loss of mass trend flattened approximately, but beyond $500^{\circ} \mathrm{C}$ and up to $1000^{\circ} \mathrm{C}$ a gain in mass trend is observed (gain in mass $=2.02 \%$ ). On the DTG curve, two broad composition peaks are observed at $235^{\circ} \mathrm{C}$ and $319^{\circ} \mathrm{C}$.

Figure 5D shows TG, DTG and DTA curves for $20 \mathrm{wt} \%$ of hybrid MMC. The DTA curve has one exothermic peak
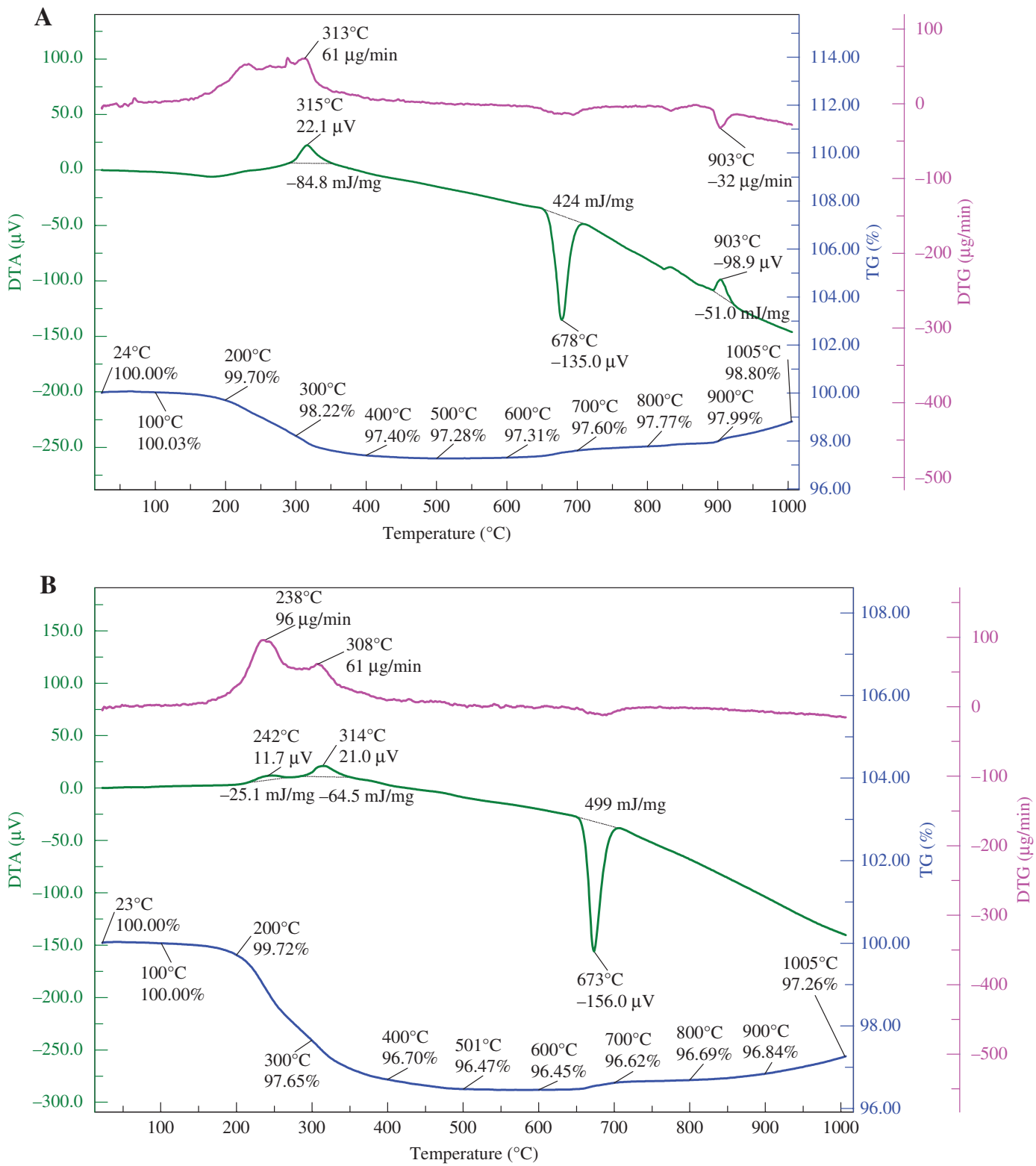

Figure 5: Thermogravimetric analysis (TG), derivative thermogravimetric analysis (DTG) and differential thermal analysis (DTA) curves for (A) $5 \mathrm{wt} \%$ hybrid composite, (B) $10 \mathrm{wt} \%$ hybrid composite, (C) $15 \mathrm{wt} \%$ hybrid composite and (D) $20 \mathrm{wt} \%$ hybrid composite. 

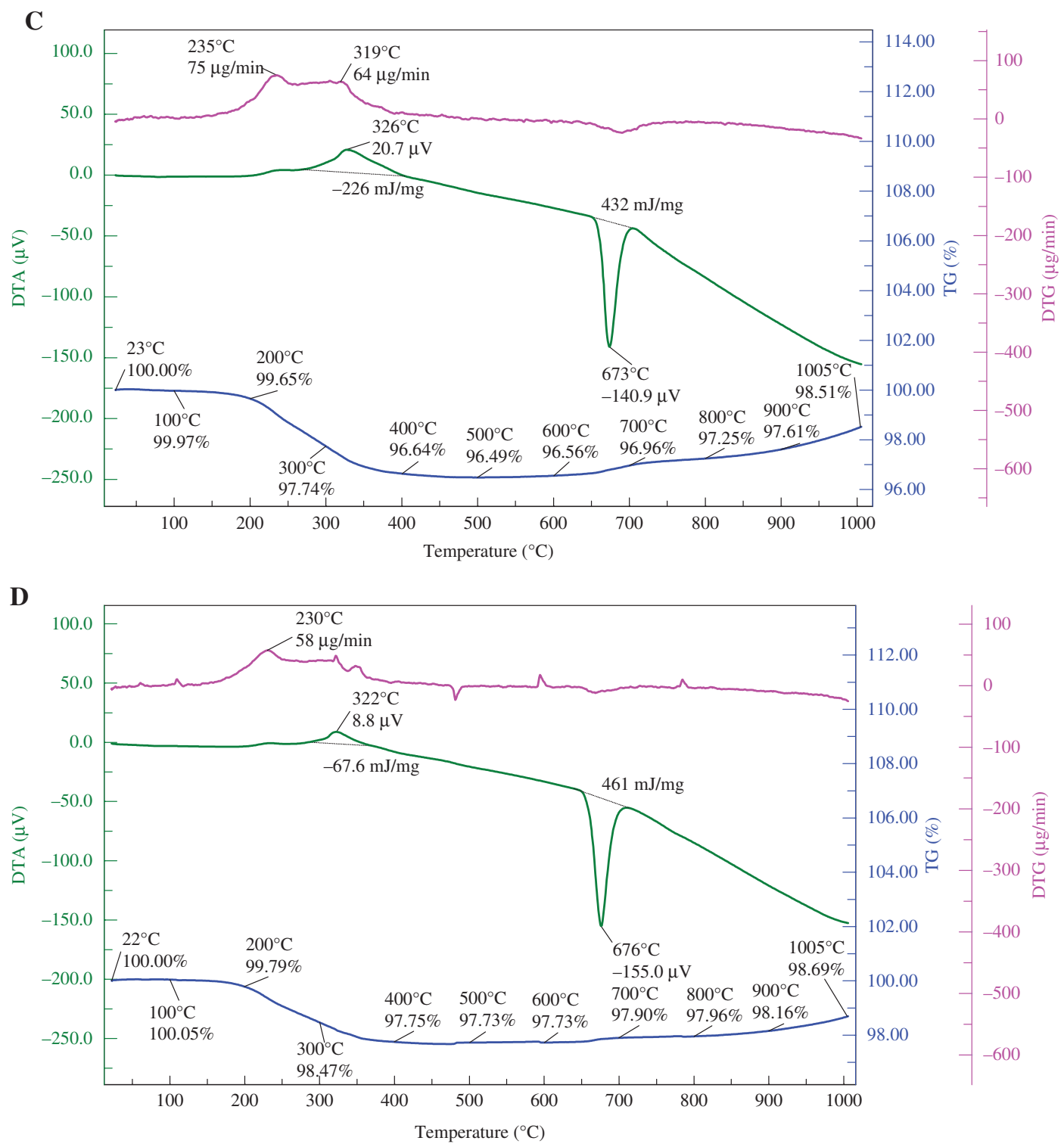

Figure 5: continued

at $322^{\circ} \mathrm{C}$ and one endothermic peak at $676^{\circ} \mathrm{C}$. The phase transformation takes place at $676^{\circ} \mathrm{C}$. The TG curve shows material at $22^{\circ} \mathrm{C}$ is $100 \%$, but a minor gain of $0.05 \%$ occurs when heating up to $100^{\circ} \mathrm{C}$. From $100^{\circ} \mathrm{C}$ to $200^{\circ} \mathrm{C}$, the trend is reversed with a minor loss of mass trend which increases steeply between $200^{\circ} \mathrm{C}$ and $400^{\circ} \mathrm{C}$ (loss of mass $=2.04 \%$ ). On heating between $400^{\circ} \mathrm{C}$ and $600^{\circ} \mathrm{C}$, the curve is almost flat and a minor gain in mass trend follows between $600^{\circ} \mathrm{C}$ and $1000^{\circ} \mathrm{C}$ (gain in mass $=0.96 \%$ ). One composition peak is observed on the DTG curve at $230^{\circ} \mathrm{C}$ followed with a few insignificant peaks.

Comparing the TG, DTA and DTG analysis of Figure 5A-D shows that there is negligible loss of material in the composite. The loss of mass at low temperature up to $100^{\circ} \mathrm{C}$ may be due to escape of the moisture which transforms to vapor on heating. At higher temperatures, some of the impurities available in the reinforcement material and the matrix metal may burn off, thus resulting in loss of mass. The gain in mass may be due to the nitriding of zinc as a constituent of the MMC by nitrogen gas available from the air supply cover being maintained during the tests.

\subsection{Mechanical behavior: tensile testing and percentage elongation}

The tensile test was carried out using the tensiometer model KIPL-PC2000 (Make: Kudale Instruments, India) facility at JMI, New Delhi, India. Three specimens from each sample of hybrid MMCs were prepared according to 


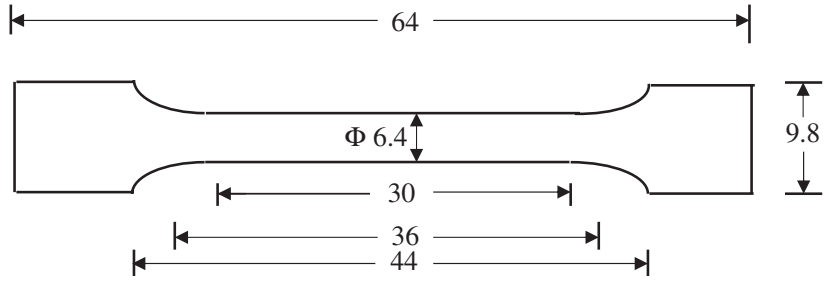

Figure 6: Tensile test specimen (all dimensions in $\mathrm{mm}$ ).

ASTM standard E8M. The dimensions of the specimen are shown in Figure 6. Also, the readings for $\%$ elongation are taken from the tensiometer.

The results of the mechanical testing are presented in Table 3. It is revealed from the test that as the wt $\%$ of hybrid reinforcements increases, the tensile strength improves. The peak value is obtained at $15 \mathrm{wt} \%$ in the hybrid composite showing an improvement of $65.7 \%$ more than the matrix alloy Al7075. The $20 \mathrm{wt} \%$ addition of reinforcement material shows a reduced trend having an improvement of only $58.2 \%$. This is due to the agglomeration of reinforcement particles taking place, leading to the creation of voids and loss of wettability. The results are taken as the average value of three tests in each sample. The reported results of hybrid MMC produced by the inert gas assisted electromagnetic stir casting process are superior to those produced by single reinforcement $\mathrm{SiC}$ [8] in the $7075 \mathrm{Al}$ alloy MMC produced by the mechanical stir casting process.

Figure 7A-D shows SEM fractographs of hybrid MMCs of $5 \mathrm{wt} \%, 10 \mathrm{wt} \%, 15 \mathrm{wt} \%$ and $20 \mathrm{wt} \%$ of the $\mathrm{Al}_{2} \mathrm{O}_{3}+\mathrm{SiC}$ reinforcements in the matrix alloy Al7075. The fractographs are taken using the scanning electron microscope LEO 435 VP operating at $15 \mathrm{kV}$ (Facility at Institute Instrumentation centre, IIT Roorkee, India), software: XPowder. Fractographic analysis of the fractured tensile specimen is carried out to understand the mechanism of material failure. Fractographs indicate that there had been strong bonding between the reinforcement particulates and the matrix material. The strong interfacial bond between reinforcement particles and the matrix alloy results in improvement of tensile strength. Good bonding between reinforcement particles and the matrix alloy also indicates good wettability between them. The fractured surface represents a dimpled structure which is a typical characteristic of tensile overload fracture

The fractographs show tearing ridges, cleavage facets, dimples, etc. The microporosity, microvoids and clustering of the reinforcement particles confirms the loss of ductility for the hybrid composite at higher wt $\%$ of the reinforcement. Generally, the strengthening is attributed to higher strength of reinforcing particles and their good bonding with the matrix alloy. Also, strength improvement takes place due to grain refinement when casting the metals through the electromagnetic stir casting process [24]. Homogeneous distribution of reinforcement in the matrix is essential for optimum mechanical properties [25]. Casting under an electromagnetic field has an influence on reinforcement particles distribution and dispersion in very effective way [26].

The microstructure examination confirms a uniform distribution of reinforcement in the matrix. The results are consistent with other researchers $[6,9,10]$.

Reduction in ductility is found as wt\% of reinforcement particles increases showing maximum reduction of $69.6 \%$ for $20 \mathrm{wt} \%$ reinforcement. This is due to the hard and brittle nature of the ceramic phase $\left(\mathrm{Al}_{2} \mathrm{O}_{3}\right.$ and $\mathrm{SiC}$ reinforcing particles).

\subsubsection{Impact strength}

For the impact test, specimens were prepared as per ASTM standard E23. Impact testing was carried out and the results are depicted in Table 3. The test results reveal that the impact strength of the hybrid MMC decreases as compared to its matrix alloy $\mathrm{Al} 7075$. The maximum reduction in impact strength is $79.4 \%$ for the 20 wt $\%$ hybrid composite specimen. This may be due to the brittle nature of the reinforcing particles acting as stress concentration areas in the hybrid MMC. The impact strength behavior of the hybrid MMC is in agreement with its reduced ductility.

Table 3: Tensile strength, \% elongation and impact energy of matrix alloy and hybrid metal matrix composite (MMC).

\begin{tabular}{|c|c|c|c|c|c|}
\hline \multirow[t]{2}{*}{ Property } & \multirow[t]{2}{*}{$\begin{array}{r}\text { Cast matrix metal } \\
7075 \text { Al alloy }\end{array}$} & \multicolumn{4}{|c|}{$\begin{array}{l}\text { Hybrid composite material with different } \\
\text { weight fractions of reinforcement }\end{array}$} \\
\hline & & $5 \mathrm{wt} \%$ & $10 w t \%$ & 15 wt $\%$ & $20 \mathrm{wt} \%$ \\
\hline Strength (MPa) & 145.6 & 201.1 & 220.8 & 241.3 & 230.4 \\
\hline Elongation (\%) & 10.2 & 8.8 & 6.4 & 4.2 & 3.1 \\
\hline Impact energy (Joule) & 24.3 & 18.1 & 10.8 & 6.2 & 5.0 \\
\hline Microhardness $\left(\mathrm{H}_{\mathrm{v}}\right)$ & 129.2 & 135.8 & 139.2 & 143.7 & 146.6 \\
\hline
\end{tabular}


A

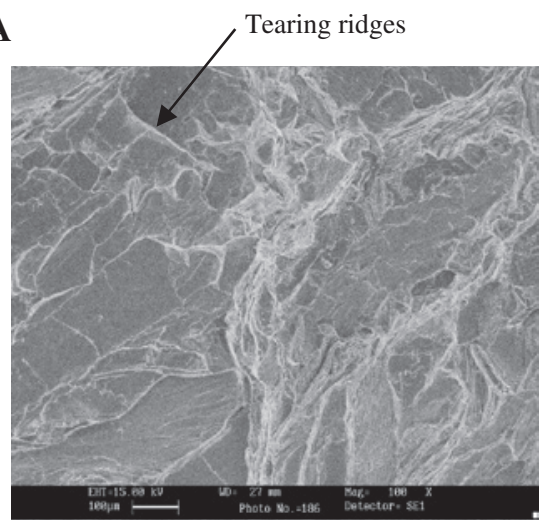

C Micro porosity

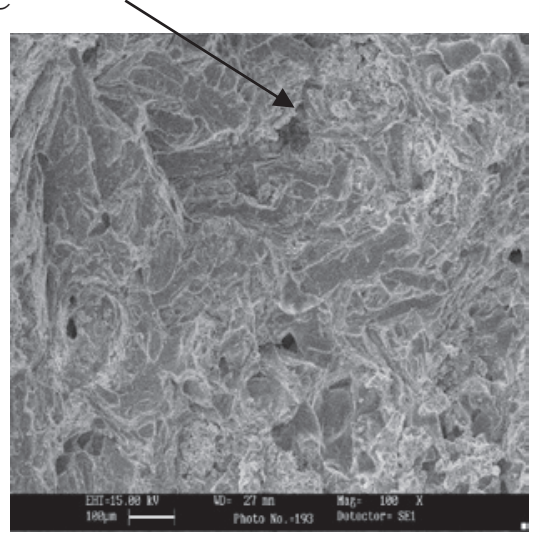

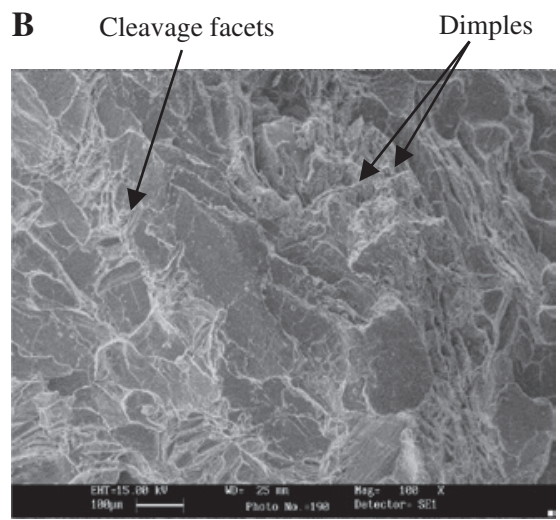

D Micro voids Clustering of particles

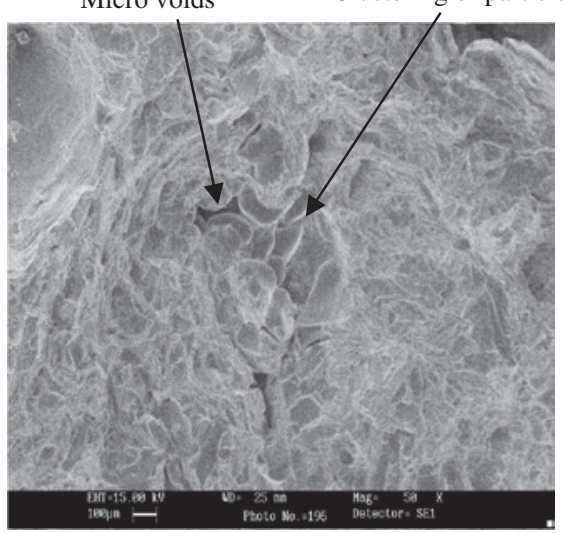

Figure 7: Scanning electron microscopy (SEM) fractograph of hybrid metal matrix composites (MMCs) of (A) $5 \%$, (B) $10 \%$, (C) $15 \%$, and (D) $20 \%$ of the $\mathrm{Al}_{2} \mathrm{O}_{3}+\mathrm{SiC}$ reinforcements in $7075 \mathrm{Al}$-alloy matrix.

\subsubsection{Microhardness}

For microhardness testing, the specimens were prepared mechanically according to ASTM standard E92. Vickers hardness testing of the hybrid MMC was done using the VLPAK2000 hardness testing system (Make: Mitutoyo, Japan), facility at JMI, New Delhi, India. The applied load was $400 \mathrm{gf}$ for $30 \mathrm{~s}$. The average value of microhardness measurements taken at three places on each specimen are tabulated in Table 3. The values indicate an increase in microhardness in the hybrid MMC as wt $\%$ of the reinforcing particles increases. The microhardness value was 146.6 Hv, maximum for $20 \mathrm{wt} \%$ of the hybrid composite showing an improvement of $13.5 \%$ when compared with an as cast metal matrix alloy. The increase in hardness of the hybrid MMC is due to high hardness value of the reinforcing materials, $\mathrm{Al}_{2} \mathrm{O}_{3}$ and $\mathrm{SiC}$, good interfacial bonding achieved between particulates and the matrix alloy and also the grain refinement of the microstructure which takes place while the melt is solidifying under the influence of an electromagnetic field.

\section{Conclusions}

The cast hybrid MMC was fabricated by the inert gas assisted electromagnetic stir casting process using $5 \mathrm{wt} \%, 10 \mathrm{wt} \%, 15 \mathrm{wt} \%$, and $20 \mathrm{wt} \%$ of $\left(\mathrm{Al}_{2} \mathrm{O}_{3}+\mathrm{SiC}\right)_{\mathrm{p}}$ in metal matrix alloy Al7075. The mechanical and microstructural characterization of the cast hybrid MMC led to the following inferences:

1. Cast hybrid MMC of $5 \mathrm{wt} \%, 10 \mathrm{wt} \%, 15 \mathrm{wt} \%$ and $20 \mathrm{wt} \%$ $\mathrm{Al}_{2} \mathrm{O}_{3}$ (MA2 Grade) and $\mathrm{SiC}$ (320 mesh size, i.e. $20-40$ $\mu \mathrm{m}$ ) both in particulate form and equal proportion in $7075 \mathrm{Al}$-alloy metal matrix was successfully fabricated using the inert gas assisted electromagnetic stir casting process.

2. Microstructures of hybrid MMC revealed a fairly uniform and homogeneous distribution of hybrid reinforcing particles of $\mathrm{Al}_{2} \mathrm{O}_{3}$ and $\mathrm{SiC}$.

3. The XRD patterns of cast hybrid MMCs for different samples confirmed the presence of the base element aluminum and the other constituents of the matrix alloy. The presence of hard phase constituents $\mathrm{Al}_{2} \mathrm{O}_{3}$ 
and $\mathrm{SiC}$ were confirmed at their respective peaks. No peaks of brittle phase $\mathrm{Al}_{4} \mathrm{C}_{3}$ were observed in the pattern.

4. TG, DTA and DTG analysis showed that there was negligible loss of material in the composite.

5. Under the mechanical properties, the tensile strength and microhardness of hybrid MMC were higher compared to its cast metal matrix 7075 Al-alloy. The tensile strength was highest for the $15 \mathrm{wt} \%$ sample showing an improvement of $65.7 \%$, and microhardness was maximum for the $20 \mathrm{wt} \%$ sample showing an improvement of $13.5 \%$. Elongation and impact strength showed a reduction trend, being lowest for the $20 \mathrm{wt} \%$ specimen showing $69.6 \%$ and $79.4 \%$ reduction, respectively.

Funding: This research did not receive any specific grant from funding agencies in the public, commercial, or not-for-profit sectors.

\section{References}

[1] Skolianos S. Mater. Sci. Eng., A 1990, 210, 72-82.

[2] Zhang XX, Deng CF, Shen YB. Mater. Lett. 2007, 61, 3504-3506.

[3] Zhang XN, Geng L, Wang GS. J. Mater. Process. Technol. 2006, $176,146-151$.

[4] Cambronero LEG, Sánchez E, Ruiz-Roman JM, Ruiz-Prieto JM. J. Mater. Process. Technol. 2003, 143-144, 378-383.

[5] Kumar S, Balasubramanian V. Wear 2008, 264, 1026-1034.
[6] Kalkanli A, Yılmaz S. Mater. Des. 2008, 29, 775-780.

[7] Karthikeyan B, Ramanathan S, Ramakrishnan V. Mater. Des. 2010, 31, S92-S95.

[8] Dasgupta R. Engineering 2010, 2, 237-256.

[9] Hossein B, Asghar A. Am. J. Mater. Sci. 2011, 1, 67-70.

[10] Karthigeyan R, Ranganath G, Sankaranarayanan V. Eur. J. Sci. Res. 2012, 68, 606-615.

[11] Deshmanya IB, Purohit GK, IOSR J. Eng. 2012, 2, 20-31.

[12] Kumar BR, Sudhir K, Das S. Int. J. Adv. Manuf. Technol. 2013, 65, 611-624.

[13] Ribes H, Dasilva R, Suery M, Breteau T. Mater. Sci. Technol. 1990, 6, 621.

[14] Thanh LN, Suery M. Scr. Metall. 1991, 25, 2781.

[15] Clyne TW. Proc ICCM-VI and ECCM-2 Elsevier Amsterdam 1987, 2, 275-286.

[16] Laurent V, Chatain D, Eustathopoulos N. Mater. Sci. Eng., A 1991, 135, 89-94.

[17] Namai T, Osawa Y, Kikuchi M. IMONO J. Jap. Foundryman's Soc. 1984, 56, 604-609.

[18] Lignon R. Rech. Aerospat. 1974, 1, 49.

[19] Escalera-Lozano R, Gutiérrez CA, Pech-Canul MA, Pech-Canul MI. Waste Manage. 2008, 28, 389-395.

[20] Lee JC, Ahn JP, Shi Z, Kim Y, Lee HI. Metall. Mater. Trans. A 2000, 31, 2361-2368.

[21] Shi Z, Yang JM, Lee JC, Zhang D, Lee HI, Wu R. Mater. Sci. Eng., A 2001, A303, 46-53.

[22] Shi Z, Ochiai S, Hojo M, Lee J, Gu M, Lee H. J. Mater. Res. 2001, 16, 400-406.

[23] Ureña A, Martínez EE, Rodrigo P, Gil L. Comput. Sci. Technol. 2004, 64, 1843-1854.

[24] Wang G, Zhao Z, Cui J, Guo Q. Acta Metall. Sin. (Engl. Lett.) 2012, 25, 160-168.

[25] Brechet Y. Acta Metall. Mater. 1991, 39, 1781.

[26] Cholewa M, Formanek B, Sozanska M, Staszewski M. J Achiev. Mater. Manuf. Eng. 2007, 25, 59-62. 